\title{
Experiments on Aerothermal Supersonic Fluid-Structure Interaction
}

\author{
Dennis Daub, Sebastian Willems, Burkard Esser, and Ali Gülhan
}

\begin{abstract}
Mastering aerothermal fluid-structure interaction (FSI) is crucial for the efficient and reliable design of future (reusable) launch vehicles. However, capabilities in this area are still quite limited. To address this issue, a multidisciplinary experimental and numerical study of such problems was conducted within SFB TRR 40. Our work during the last funding period was focused on studying the effects of moderate and high thermal loads. This paper provides an overview of our experiments on FSI including structural dynamics and thermal effects for configurations in two different flow regimes. The first setup was designed to study the combined effects of thermal and pressure loads. We investigated a range of conditions including shock-wave/boundary-layer interaction (SWBLI) with various incident shock angles leading to, in some cases, large flow separation with high amplitude temperature dependent panel oscillations. The respective aerothermal loads were studied in detail using a rigid reference panel. The second setup allowed us to study the effects of severe heating leading to plastic deformation of the structure. We obtained severe localized heating resulting in partly plastic deformations of more than 12 times the panel thickness. Furthermore, the effects of repeated load cycles were studied.
\end{abstract}

\section{Introduction}

Vehicles traveling through earth's atmosphere at supersonic and hypersonic speeds are subjected to severe aerothermal loads from the surrounding flow field and in many cases also from their propulsion system. Building such vehicles requires very light weight design inevitably prone to structural deformation that can in turn alter the flow field and aerothermal loads, which we call fluid-structure interaction (FSI). Such interactions can show a wide range of non-linear and/or path dependent behavior [40, 53], making safe and efficient design a major challenge. Furthermore aerodynamic

D. Daub (凶) $\cdot$ S. Willems · B. Esser · A. Gülhan

Supersonic and Hypersonic Technology Department, German Aerospace Center (DLR), Institute of Aerodynamics and Flow Technology, Linder Höhe, 51147 Köln, Germany

e-mail: dennis.daub@dlr.de

(C) The Author(s) 2021

N. A. Adams et al. (eds.), Future Space-Transport-System Components

under High Thermal and Mechanical Loads, Notes on Numerical Fluid Mechanics

and Multidisciplinary Design 146, https://doi.org/10.1007/978-3-030-53847-7_21 
problems in many cases crucial for the aerothermodynamic loads like boundary layer transition and shock-wave/boundary-layer interaction (SWBLI) are not fully understood [38]. FSI can lead to degraded performance or structural failure [3, 47, $52,58]$ and has done so from the earliest days of aviation [20] to modern launch vehicles [15, 31].

To solve these problems, multidisciplinary fluid-structure coupled numerical tools to predict FSI are essential for vehicle design and development, especially considering the current interest in reusable systems. But despite significant advances in simulation methods, FSI remains a major challenge [28, 38, 52, 53].

To address this issue, a multidisciplinary experimental and numerical study of such problems was conducted within SFB TRR 40 [23, 26, 37, 44, 45, 60].

Development and validation of coupled numerical tools depends on the availability of high quality reference experiments [39, 52, 54]. However, only very few such studies can be found in literature. Some research was focused on preventing panel flutter [13, 14]. Other experimental results were obtained from flight experiments too complex for validation of basic methods (e.g. [29, 41]). For the purpose of fundamental analysis and validation of numerical models, only basic geometric configurations are suitable.

\subsection{FSI and SWBLI}

FSI with SWBLI is a case of particular interest because of the induced high pressure and temperature gradients as well as its complexity due to the combination of inherent SWBLI dynamics [12] with structural dynamics and its relevance in engineering application for rocket nozzles [19] and supersonic flight [38].

Early experiments were conducted by [35]. They measured pressure fluctuations and the response of an elastic panel induced by incident SWBLI. Pressure fluctuations and panel movements were found to be increased compared to a case that was solely excited by a turbulent boundary layer. Other classic experiments were conducted by [4]. They found a large increase in panel response for separated flow fields.

Recent notable contributions to the field using modern high speed instrumentation were made by [50, 51]. An experimental setup similar to [35] consisting of an incident SWBLI and an elastic panel was used. High speed full field pressure and displacement measurements through digital image correlation (DIC) [1, 2] were used to obtain data for detailed analysis and validation of numerical FSI simulations. Panel response was drastically changed in comparison to the no-shock case and, depending on the shock position, the maximum amplitude of the panel deformation was significantly increased. Numerical results by [21, 22] suggest that while good agreement on mean quantities was achieved it is crucial for the prediction of the dynamics of the coupled system to take into account the intrinsic unsteadiness of SWBLI. FSI experiments with SWBLI with a different focus were conducted by $[5,6]$. They studied the effects of an incident shock on cantilevered plates resembling control surfaces. 
Extensive numerical studies were conducted by [56, 57]. Variations of incident shock configurations were investigated using Euler and RANS methods. They found self-sustained oscillations of the structure and showed that the dynamic pressure necessary decreases with increasing shock strength. Another recent numerical study on FSI with laminar SWBLI was done by [49]. They observed self-excited oscillations which increased in amplitude with increase of incident shock strength.

Experiments similar to $[50,51]$ with a slightly different approach and focus were conducted at DLR within SFB TRR 40 by $[59,60]$. Like $[35,51]$ an incident SWBLI interacts with an elastic panel. But unlike in the other configurations a flat plate dividing the wind tunnel test section was used to obtain a new boundary layer while [35, 51] used the facility boundary layer. This approach makes construction and instrumentation of the elastic structure more difficult but provides more reliable boundary conditions on the flow side for comparison to high fidelity numerical methods like LES. Furthermore a panel clamped only at the upstream and downstream sides was used to reduce $3 \mathrm{D}$ effects. Practical limits to this approach are the finite width of the panel and of the test section. Due to the width of the shock generator the incident shock on the panel showed strong 3D behavior. Consequently, the setup was modified by using a rotatable shock generator spanning the full width of the test section to obtain a more 2D flow field as well as undeformed initial conditions for the panel [8, 9]. Furthermore the new shock generator allows to quickly alter the incident shock angle allowing forced excitation of the structure. These changes made it possible to compare the obtained data both to LES flow simulations by [46] as well as coupled FSI simulations [44]. Static and dynamic pressure measurements for the rigid case showed very good agreement demonstrating both the reliability of the obtained flow field measurements as well as of the LES. The comparison of experiment and LES-coupled FSI simulation is the only such attempt known to the authors.

The present study extends the available data set to higher total temperatures where combined thermal and pressure loads interact with the structure (Sect. 2).

\subsection{High Temperature FSI}

Despite a rich history of development and research of thermal structures including such prominent examples as the X-15, National Aerospace Plane, Sänger, Space Shuttle and current ventures into hypersonics only very little experimental data on high temperature generic configurations suitable for fundamental research and validation of coupled numerical tools is available.

References [32, 48] investigated aerothermal FSI of a generic C/C-SiC structure similar to a re-entry vehicle nose using digital image correlation (DIC) at DLR's L3K facility for the first time. [48] as well as [24] also conducted experiments on heating of gaps and control surfaces in similar conditions that were compared to FSI simulations [33, 34, 48] showing that coupled simulations are crucial for predicting heating of complex geometries and/or areas with strong thermal gradients. 
Within SFB TRR 40, experiments with focus on thermal FSI in high enthalpy conditions were conducted by $[60,61]$. They established a data base on structural heating for several generic rigid $\mathrm{C} / \mathrm{C}-\mathrm{SiC}$ geometries. Theses experimental results showed good agreement with thermally coupled simulations.

References [27, 42] investigated a metallic structure using DIC and obtained significant plastic deformation. These results were compared to coupled simulations demonstrating the feasibility of this approach. The present study is a follow-up to these experiments. The obtained data will serve as reference for improved thermoplastic coupled simulations by [37]. The overview given in this paper is based on the full results published in [7].

Numerical work in this area was also done by [55], who investigated viscoplastic deformation due to localized heating on hypersonic structures as well as the increase of aerodynamic heating due to deformation of the structure [54]. Reference [30] conducted coupled simulations and suggested using metallic thermal protection systems for reusable launch vehicles.

Reference [17] conducted an interesting related study on buckling induced by localized heating of constrained panels but without aerodynamic loads.

\section{Experiments on Aerothermoelastic FSI with SWBLI}

\subsection{Wind Tunnel H2K}

To obtain flow conditions suitable for studying a combination of pressure-driven structural dynamics as well as thermal effects a facility is required that provides both sufficient dynamic pressure and total temperature. The experiments were thus conducted in the H2K wind tunnel at DLR, Cologne, a versatile blow down facility with a free jet test section (Fig. 1) [43]. Resistance heaters are used to adjust the total temperature. The nozzle can be exchanged to vary the Mach number. The nozzle exit diameter is $600 \mathrm{~mm}$. The results presented in this paper were obtained at a Mach number of 5.33, total temperature of $390 \mathrm{~K}$ and a total pressure of $1250 \mathrm{kPa}$ resulting in a Reynolds number of about $19.3 \times 10^{6} / \mathrm{m}$.

\subsection{Wind Tunnel Model and Instrumentation}

Figure 2 shows a Schlieren image during a wind tunnel run to clarify the wind tunnel model configuration and basic properties of the flow field. The model is positioned in the free jet of the $\mathrm{H} 2 \mathrm{~K}$ facility. On the bottom of the image, there is a flat plate that carries flush mounted elastic or rigid inserts for FSI or reference experiments. On top, there is a shock generator that can be positioned at various angles and locations or removed entirely. The free surface area of the elastic inserts is about $300 \mathrm{~mm} \times$ 


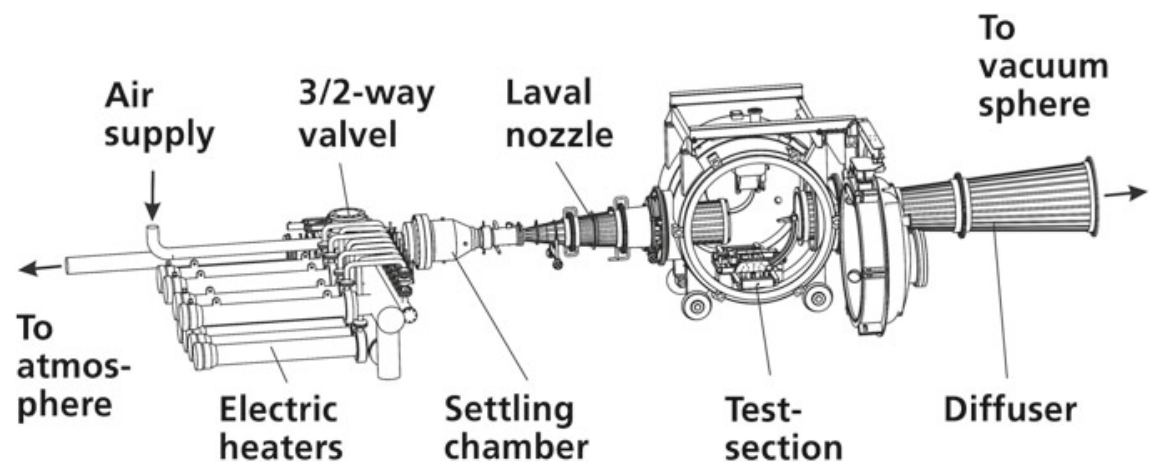

Fig. 1 Hypersonic blow down wind tunnel H2K at DLR Cologne

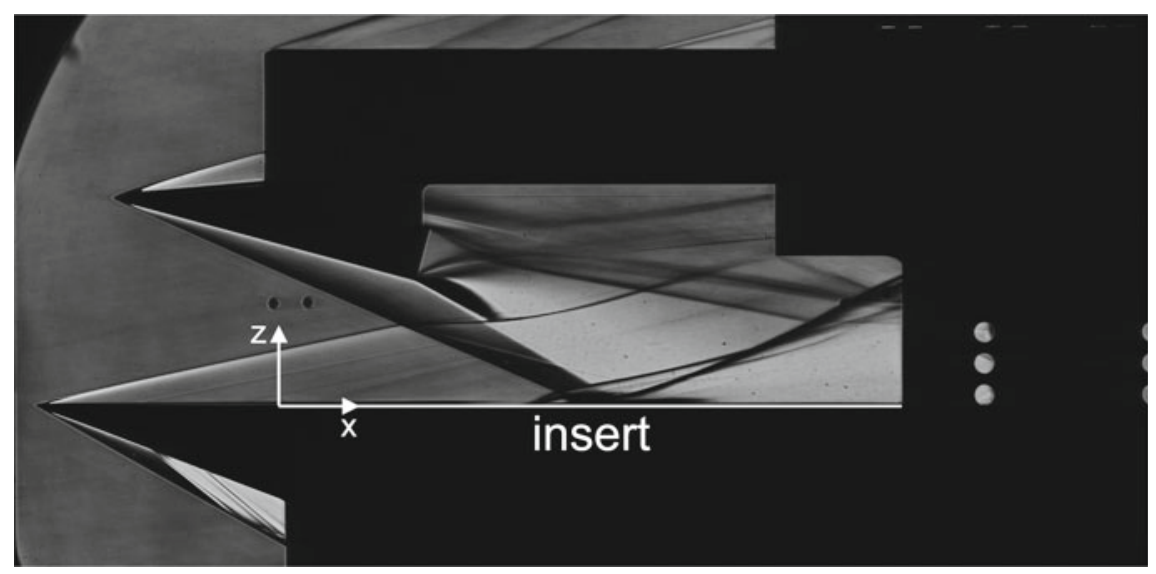

Fig. 2 Example Schlieren image

$200 \mathrm{~mm}$ (marked in white in Fig. 2). Panels of $0.3 \mathrm{~mm}$ and $0.7 \mathrm{~mm}$ thickness made of stainless steel were used. The origin of the coordinate system is located at the upstream end of the elastic section $115 \mathrm{~mm}$ from the leading edge. Refer to [11] for a detailed description.

The deformation of the elastic panels was measured using high speed capacitive distance sensors [11]. To simultaneously observe the flow field, a high speed camera was used to record Schlieren images. A new Schlieren setup was designed and built to achieve optimal results [10]. On the rigid reference insert, various low and high speed pressure sensors were used along with an IR camera to study heating. 

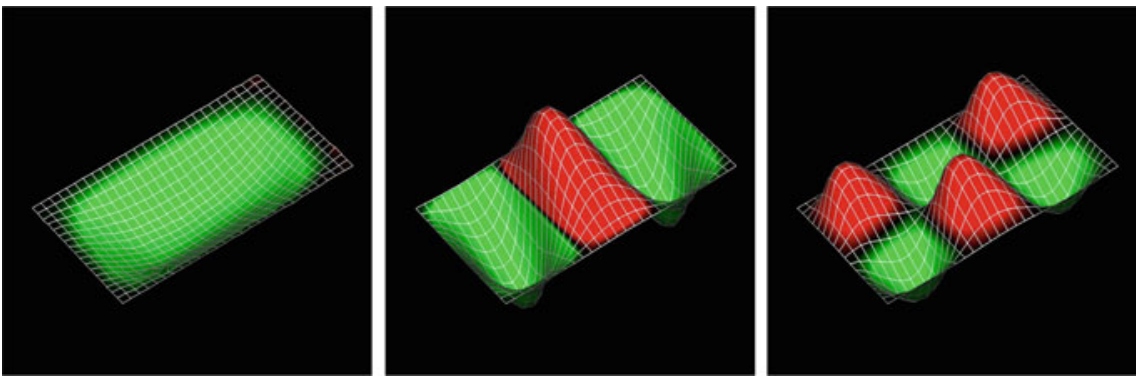

Fig. 3 Examples of measured modes $(255,435,695 \mathrm{~Hz})$ of the $0.7 \mathrm{~mm}$ panel without flow (amplitudes not to scale)

\subsection{Properties of the Elastic Panel}

The properties of the elastic panels, which are crucial for detailed analysis and modeling, were investigated using an automatic impact hammer with a force sensor and an accelerometer as well as a laser doppler velocimeter. Exemplary results are shown in Fig. 3.

\subsection{Experimental Results}

We conducted several experimental campaigns to study structural heating and static and dynamic pressure loads on a rigid reference structure as well as structural dynamics of thin panels under various flow conditions.

Figures $4 \mathrm{a}-\mathrm{c}$ and $5 \mathrm{a}-\mathrm{c}$ illustrate exemplary results for the $0.7 \mathrm{~mm}$ and $0.3 \mathrm{~mm}$ panels with and without shock generator. They each show an instantaneous shadowgraph image of the flow field, the recorded panel displacement measurements on three locations on the panel (at $\mathrm{x}=75 \mathrm{~mm}, 155 \mathrm{~mm}, 225 \mathrm{~mm}$ ) as well as a spectrogram of the center sensor displacement. The time series plots show that large amplitude selfsustained oscillations were obtained in both cases and both show transient behavior caused by the heating of the panel that eventually even stops the panel oscillation while the wind tunnel is still running at unchanged conditions. During the experiment, even a small change in surface temperature of less than $100 \mathrm{~K}$ in the case with SWBLI and less than $40 \mathrm{~K}$ for the case without SWBLI (see [11]) brings about a fundamental change in the behavior of the panel, further underlining the importance of coupled treatment of such problems for vehicle design. This temperature range is well within reach during a supersonic retropropulsion maneuver [16].

The spectrograms Figs. $4 \mathrm{c}$ and $5 \mathrm{c}$ show that, in addition to starting and stopping significant panel oscillations, shifts in the the detected frequencies occur. The obtained data sets are currently analyzed in detail with regards to heating of the panel, static and dynamic pressure loads from the SWBLI and structural dynamics. 
a
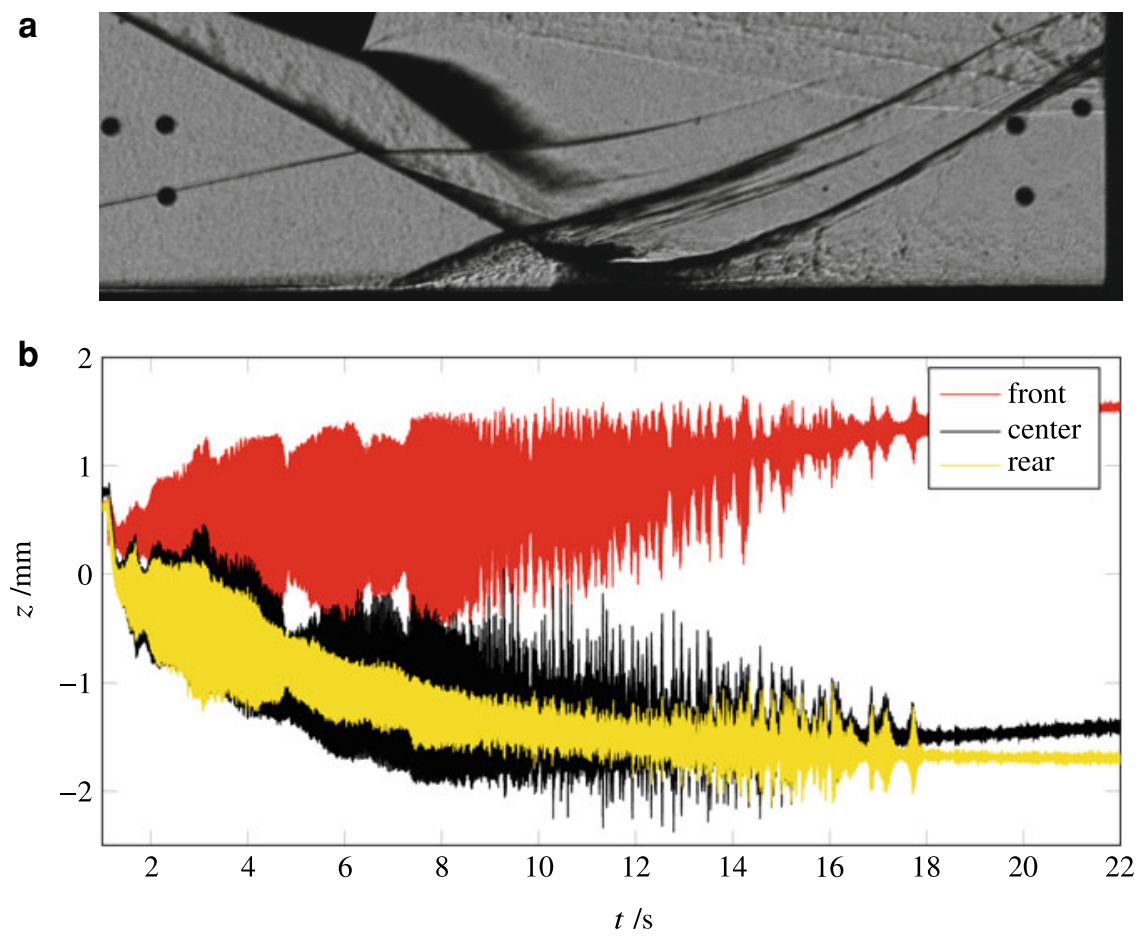

C

$\log (P S D) / \log \left(\mathrm{mm}^{2} / \mathrm{kHz}\right)$
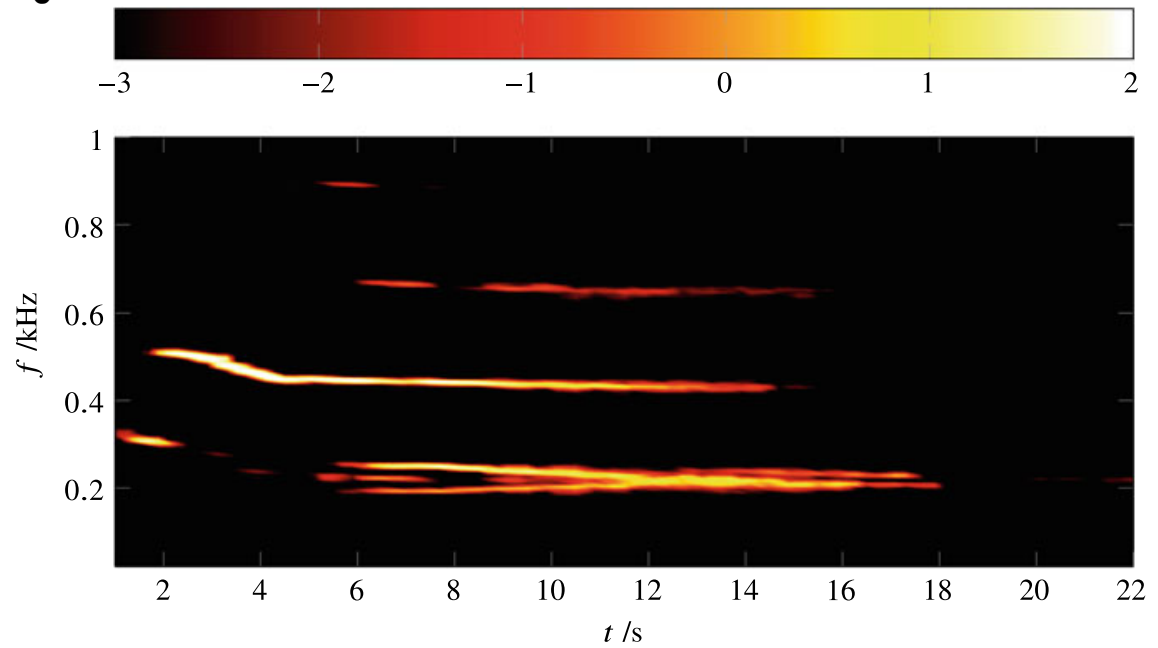

Fig. 4 a Instantaneous shadowgraph image $-0.7 \mathrm{~mm}$ panel, $20^{\circ}$ shock generator angle. b Time series, displacement sensors $-0.7 \mathrm{~mm}$ panel, $20^{\circ}$ shock generator angle. c Spectrogram, central displacement sensor $-0.7 \mathrm{~mm}$ panel, $20^{\circ}$ shock generator angle 
a
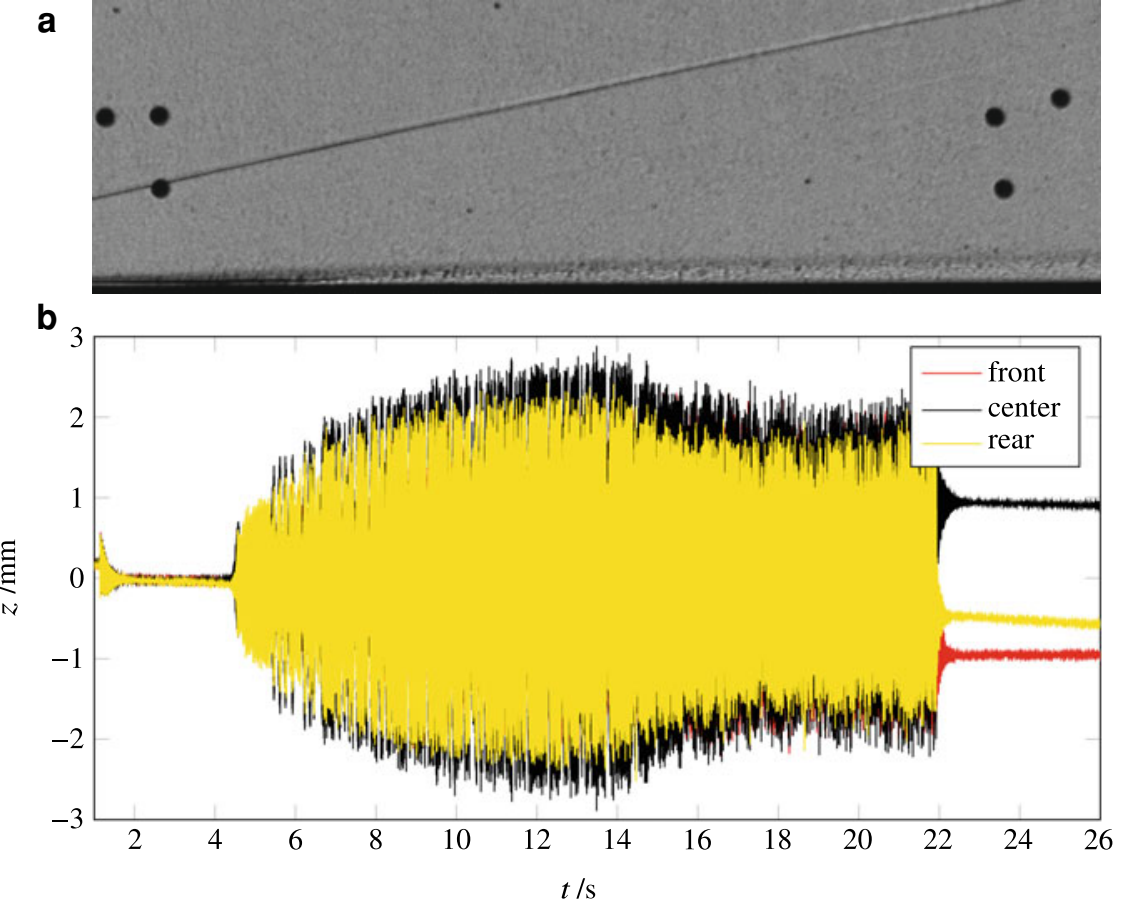

$P S D /\left(\mathrm{mm}^{2} / \mathrm{kHz}\right)$
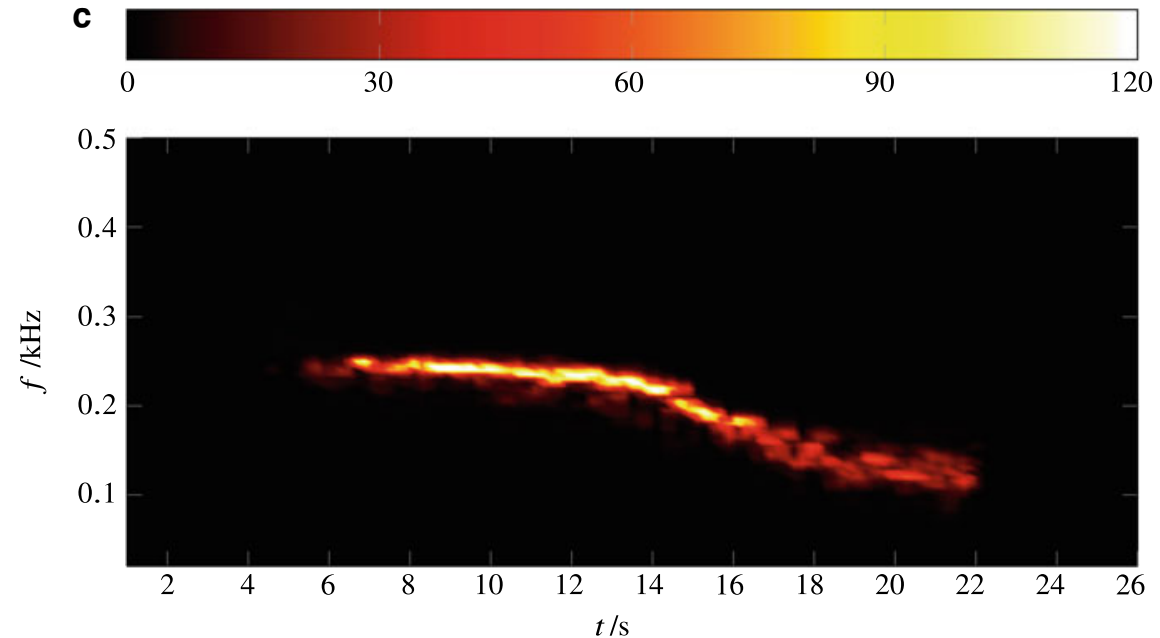

Fig. 5 a Instantaneous shadowgraph image $-0.3 \mathrm{~mm}$ panel, without shock generator. b Time series, displacement sensors $-0.3 \mathrm{~mm}$ panel, without shock generator. $\mathbf{c}$ Spectrogram, central displacement sensor $-0.3 \mathrm{~mm}$ panel, without shock generator 
The comparison of the high-speed shadowgraph recordings to the observed panel movements will be of particular interest.

This study provides an important and novel data set with regards to the setup of coupled simulations as well as design of future experiments. To the authors' knowledge, the only other studies where thermal effects were considered for a similar configuration were done by [52], but at lower Mach numbers complementing the present results.

\section{Experiments on High Temperature FSI with Plastic Deformation}

\subsection{Arc-Heated Wind Tunnel L3K}

The arc-heated wind tunnel L3K at DLR, Cologne (Fig. 6) [25] was used to obtain the aerothermal loads required for significant plastic deformation. This facility provides a hypersonic free jet at total temperatures between 4000 and $7000 \mathrm{~K}$. The experiments were conducted at $20^{\circ}$ angle of attack at the flow conditions shown in Table 1.

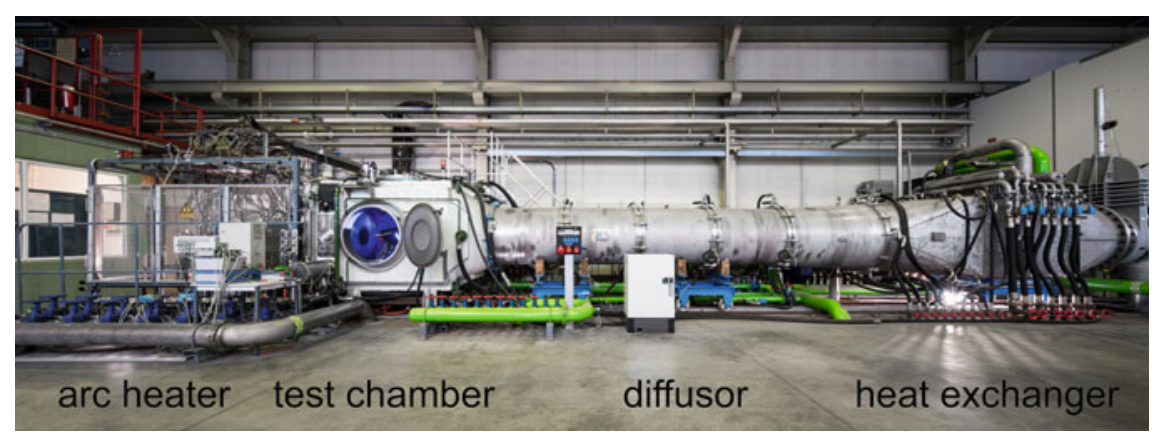

Fig. 6 Arc-heated wind tunnel L3K at DLR, Cologne

Table 1 Computed flow conditions

\begin{tabular}{l|l|l|l}
\hline Flow parameters & Flow composition \\
\hline Variable & Value & Species & Mass Fraction \\
\hline$M a_{\infty}$ & 7.7 & $\mathrm{~N}_{2}$ & 0.755 \\
\hline$p_{\infty}$ & $50.3 \mathrm{~Pa}$ & $\mathrm{O}_{2}$ & 0.021 \\
\hline$T_{\infty}$ & $477 \mathrm{~K}$ & $\mathrm{NO}$ & 0.022 \\
\hline$v_{\infty}$ & $3756 \mathrm{~m} / \mathrm{s}$ & $\mathrm{N}$ & $<0.0001$ \\
\hline & & $\mathrm{O}$ & 0.202 \\
\hline
\end{tabular}



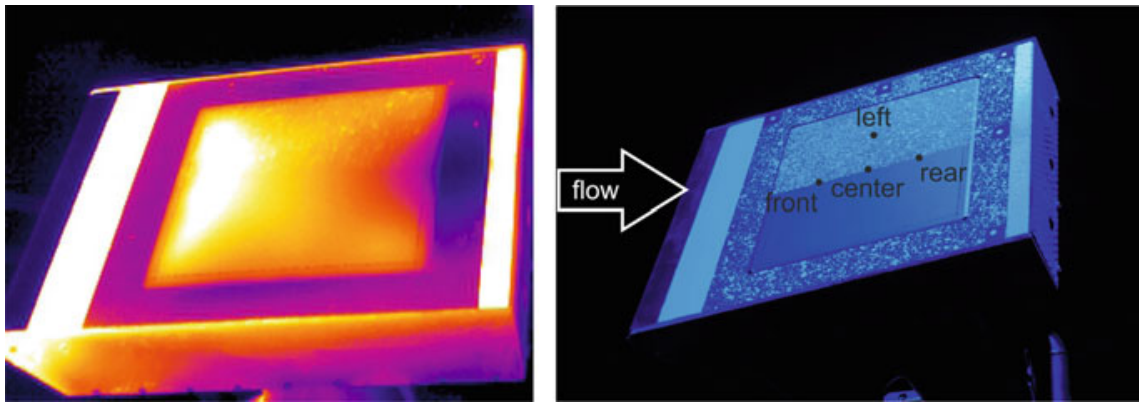

Fig. 7 Wind tunnel model (Unprocessed infrared image, Reference sensor positions and DIC marking)

\subsection{Wind Tunnel Model and Instrumentation}

Figure 7 shows an infrared image during a wind tunnel run to clarify the wind tunnel model configuration. The model is positioned in the free jet of the L3K facility. It consists of a cooled nose (left) and support structure (underneath) that holds a thick frame in which the test panels $(200 \times 200 \mathrm{~mm}$ of $1 \mathrm{~mm}$ or $2 \mathrm{~mm}$ thickness, made of Incoloy $800 \mathrm{H}$ ) were mounted. The basic concept is that the thin panel with low thermal capacity heats up quickly and buckles against the thick frame of high thermal capacity that remains much colder. Thus in Fig. 7 the cold frame and warm panel can be seen clearly. Refer to [7] for a full description.

During the experiments, time resolved full field surface temperature and displacement measurements were conducted using an IR camera and DIC (Fig. 7) [7]. For both deformation and temperature, additional independent measurements were conducted using laser triangulation sensors and pyrometers.

\subsection{Experimental Results}

We conducted several experimental campaigns to obtain data on high temperature FSI including plastic deformation of the structure. An example of the results obtained is given in Figs. 8, 9a, b. Refer to [7] for a full description of the experiments. ${ }^{1}$

Figure 8 shows the deformation of a $1 \mathrm{~mm}$ panel during one experiment (sensor positions see Fig. 7). At $0 \mathrm{~s}$ the model reached its position in the wind tunnel jet. The panel quickly buckled into the flow field with declining rate of change until reaching an equilibrium state. The jet was shut down at $120 \mathrm{~s}$. Then the cool-down of the structure was observed in vacuum conditions.

Figure $9 a, b$ show the surface deformation and temperature of this panel after a $120 \mathrm{~s}$ wind tunnel run just before jet shut-down. Maximum deformation occurs upstream of the panel center unlike for a panel under uniform temperature load.

\footnotetext{
${ }^{1}$ The data shown is referred to as Run 5 in [7].
} 
Fig. 8 Comparison of DIC and laser displacement measurements

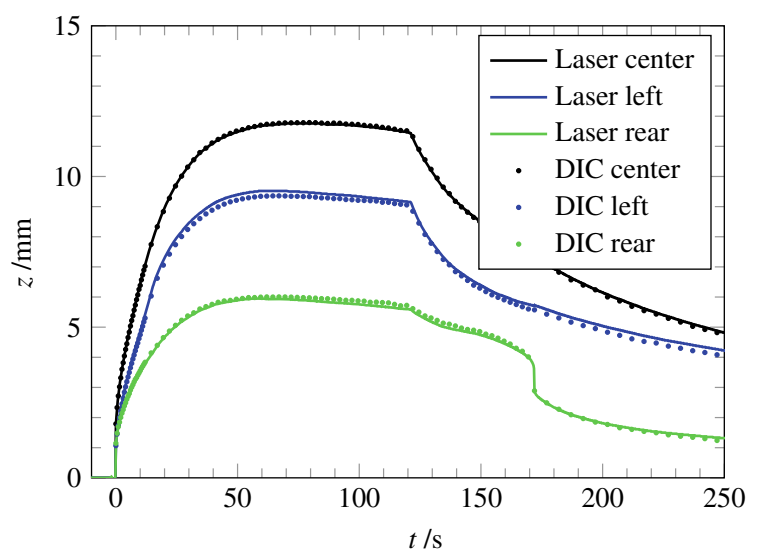

Correspondingly, the maximum temperature is reached upstream of the center in the area where the panel buckles into the flow causing a local increase in heating of the structure underlining the need for fluid-structure coupled treatment of such problems.

This time-resolved full field temperature and deformation data set is well suited for comparison to numerical simulations. The data was validated by additional measurements with independent instrumentation, e.g. external DIC and internal laser triangulation sensors (Fig. 8). Large plastic deformation of the structures was obtained, clearly showing a significant effect of the deformation on the temperature field. Furthermore the panels were subjected to repeated load cycles. For the comparison of the experiments to numerical simulations conducted within SFB TRR 40 see [36]. For results on the use of thermal barrier coating see [18].

\section{Conclusion}

We conducted experimental FSI studies on thermally transient self-sustained oscillations/flutter with and without incident shock as well as plastic buckling of panels in hypersonic flow.

The former is the only experimental study to date to consider FSI with SWBLI for a panel configuration in hypersonic flow providing insight into the influence of the panel temperature and SWBLI on structural dynamics. Only few studies at lower Mach numbers were previously available in the literature, in most cases without investigation of thermal effects. The results suggest that both a temperature dependent onset and ending of high amplitude oscillations occurred in several cases. This novel data set will be analyzed in detail especially with regards to the thermal and pressure effects of the SWBLI on the panel dynamics. The analysis of the high speed shadowgraph recordings will be valuable with regards to the dynamics of the SWBLI. These experiments provide an excellent starting point for further studies on 
a

z $/ \mathrm{mm}$
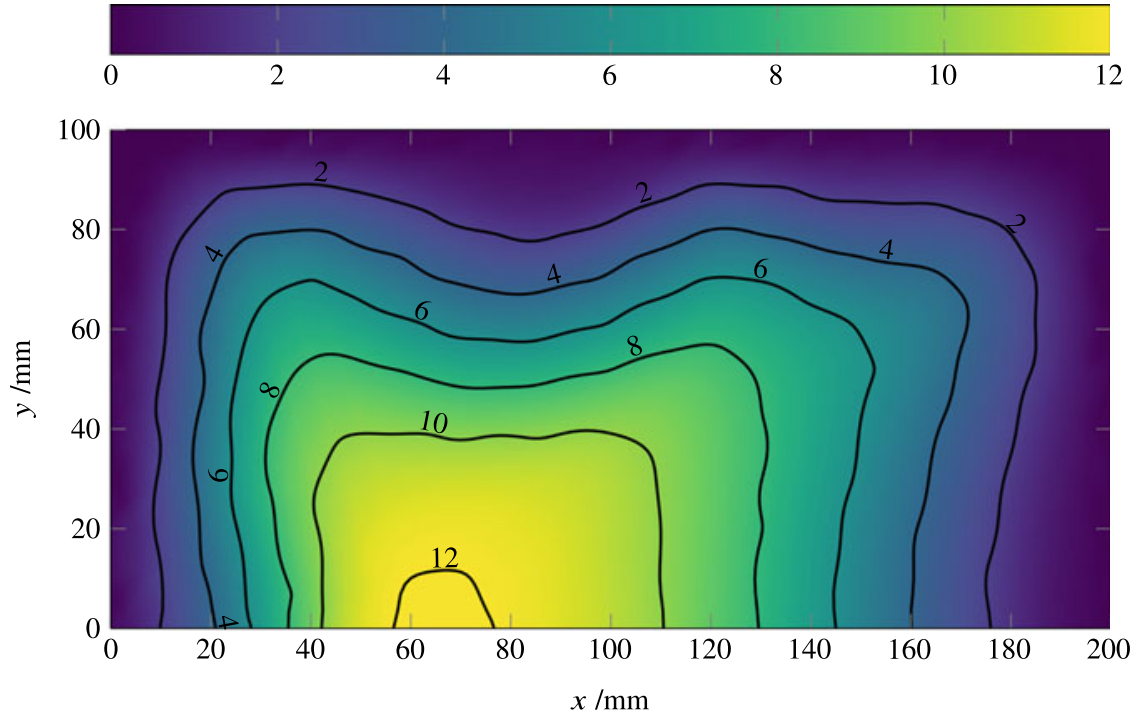

b

$T / \mathrm{K}$
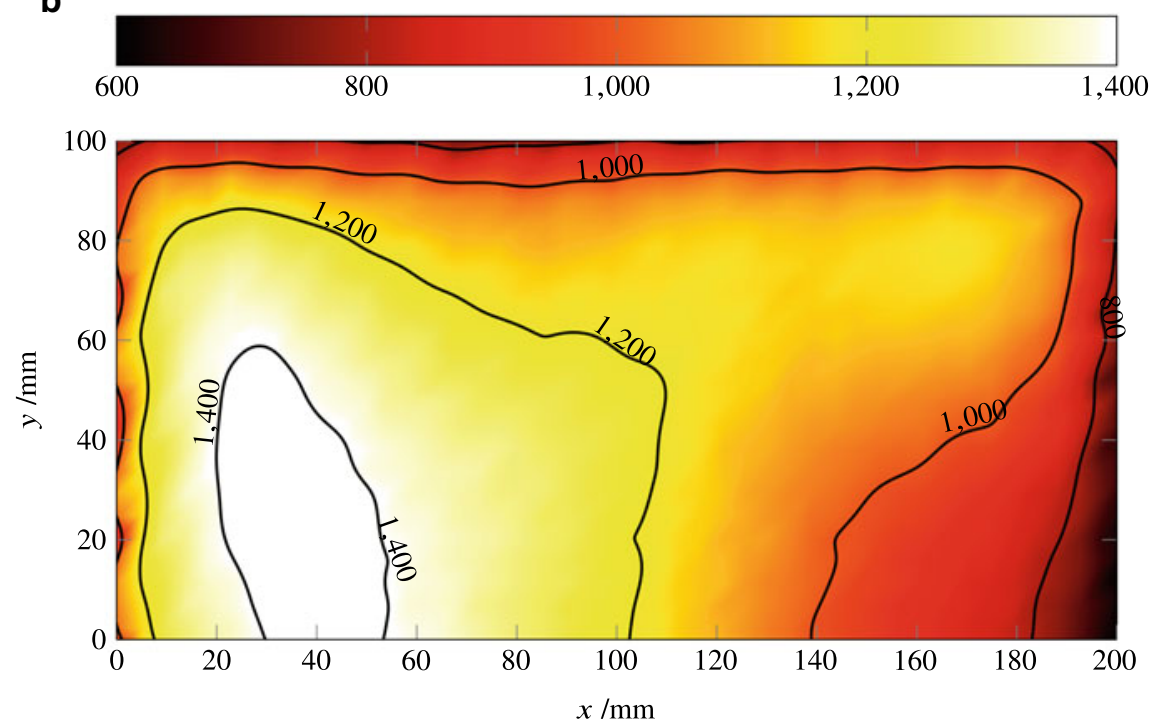

Fig. 9 a Deformation contour of a $1 \mathrm{~mm}$ panel after $120 \mathrm{~s}$. b Temperature distribution of a $1 \mathrm{~mm}$ panel after $120 \mathrm{~s}$ 
an extended range of flow conditions and structural configurations. FSI with transitional SWBLI with its effect on heating might be a point of particular interest. Full field measurement techniques such as high speed DIC and PIV could provide a challenging but promising addition to the present instrumentation setup.

The latter study on FSI in high enthalpy conditions including plastic deformation provided validated time-resolved full field measurements of both temperature and deformation fields, as well as insights into dynamic effects and repeated loads cycles. This data is used for validation of the multidisciplinary coupled simulations conducted with our cooperation partners within SFB TRR 40 [36]. Furthermore, this configuration was used as a test case for the application of thermal barrier coating developed in SFB TRR 40 [18].

These results contribute to the development of future (reusable) launch vehicles and supersonic aircraft by improving general understanding of multidisciplinary FSI problems as well as by providing validation data for tools needed to efficiently and safely design such vehicles.

Acknowledgements The authors gratefully acknowledge the help and advice of the H2K and L3K operations teams of the Supersonic and Hypersonic Technology Department. Financial support has been provided by the German Research Foundation (Deutsche Forschungsgemeinschaft - DFG) in the framework of the Sonderforschungsbereich Transregio 40.

\section{References}

1. Beberniss, T., Eason, T.G., Spottswood, S.M.: High-speed 3D digital image correlation measurement of long-duration random vibration; recent advancements and noted limitations. In: Proceedings of ISMA2012-USD2012 (2012)

2. Beberniss, T.: Experimental Study on the Feasibility of High-Speed 3-Dimensional Digital Image Correlation for Wide-Band Random Vibration Measurement. Ph.D. thesis, University of Cincinnati (2018)

3. Blevins, R.D., Holehouse, I., Wentz, K.R.: Thermoacoustic loads and fatigue of hypersonic vehicle skin panels. Journal of Aircraft 30(6), 971-978 (1993). https://doi.org/10.2514/3.46441

4. Coe, C.F., Chyu, W.J.: Pressure-Fluctuation Inputs and Response of Panels Underlying Attached and Separated Supersonic Turbulent Boundary Layers. Tech. Rep. NASA TM X62,189, NASA Ames Research Center (1972)

5. Currao, G.M.D., McQuellin, L.P., Neely, A.J., Zander, F., Buttsworth, D., McNamara, J.J., Iahn, I.: Oscillating Shock Impinging on a Flat Plate at Mach 6. In: AIAA Aviation 2019 Forum. American Institute of Aeronautics and Astronautics (2019). https://doi.org/10.2514/6. 2019-3077

6. Currao, G.M.D., Neely, A.J., Kennell, C.M., Gai, S.L., Buttsworth, D.R.: Hypersonic FluidStructure Interaction on a Cantilevered Plate with Shock Impingement. AIAA Journal pp. 1-16 (2019). https://doi.org/10.2514/1.j058375

7. Daub, D., Esser, B., Gülhan, A.: Experiments on High Temperature Hypersonic Fluid-Structure Interaction with Plastic Deformation. AIAA Journal (in press) (2020)

8. Daub, D., Willems, S., Gülhan, A.: Experimental results on unsteady shock-wave/boundarylayer interaction induced by an impinging shock. CEAS Space Journal 8(1), 3-12 (2016). https://doi.org/10.1007/s12567-015-0102-4

9. Daub, D., Willems, S., Gülhan, A.: Experiments on the Interaction of a Fast-Moving Shock with an Elastic Panel. AIAA Journal 54(2), 670-678 (2016). https://doi.org/10.2514/1.J054233 
10. Daub, D., Esser, B., Willems, S., Gülhan, A.: Experiments on Thermomechanical FluidStructure Interaction in Supersonic Flows. In: Stemmer, C., Adams, N.A., Haidn, O.J., Radespiel, R., Sattelmayer, T., Schröder, W., Weigand, B. (eds.) SFB/TRR40 Annual Report, pp. 243-254. Technische Universität München, Garching bei München, Lehrstuhl für Aerodynamik und Strömungsmechanik (2017)

11. Daub, D., Willems, S., Esser, B., Gülhan, A.: Experiments on Elastic Aerothermal Fluid/Structure Interaction in Supersonic Flows. In: Stemmer, C., Adams, N.A., Haidn, O.J., Radespiel, R., Sattelmayer, T., Schröder, W., Weigand, B. (eds.) SFB/TRR40 Annual Report, pp. 277-290. Technische Universität München, Garching bei München, Lehrstuhl für Aerodynamik und Strömungsmechanik (2019)

12. Dolling, D.S.: Fifty Years of Shock-Wave/Boundary-Layer Interaction Research: What Next? AIAA Journal 39(8), 1517-1531 (2001). https://doi.org/10.2514/2.1476

13. Dowell, E.H.: Aeroelasticity of plates and shells. Noordhoff International Publishing (1975)

14. Dowell, E.H.: Panel flutter - A review of the aeroelastic stability of plates and shells. AIAA Journal 8(3), 385-399 (1970). https://doi.org/10.2514/3.5680

15. Drogoul, S.: From the Failure to the Success - The Return to Flight of the Ariane 5 ECA Launcher. In: 56th International Astronautical Congress. IAF (2005). https://doi.org/10.2514/ 6.iac-05-d2.2.08

16. Ecker, T., Karl, S., Dumont, E., Stappert, S., Krause, D.: Numerical Study on the Thermal Loads During a Supersonic Rocket Retropropulsion Maneuver. Journal of Spacecraft and Rockets (2019). https://doi.org/10.2514/1.a34486

17. Ehrhardt, D.A., Virgin, L.N.: Experiments on the thermal post-buckling of panels, including localized heating. Journal of Sound and Vibration 439, 300-309 (2019). https://doi.org/10. 1016/j.jsv.2018.08.043

18. Fiedler, T., Rösler, J., Bäker, M., Hötte, F., v. Sethe, C., Daub, D., Haupt, M., Haidn, O., Esser, B., Gülhan, A.: Future Space-Transport-System Components under High Thermal and Mechanical Loads, chap. Mechanical Integrity of Thermal Barrier Coatings - Coating Development and Micromechanics. Springer (2020)

19. Frey, M.: Behandlung von Strömungsproblemen in Raketendüsen bei Überexpansion. Dissertation, Universität Stuttgart (2001). https://doi.org/10.18419/opus-3650

20. Garrick, I.E., III, W.H.R.: Historical Development of Aircraft Flutter. Journal of Aircraft 18(11), 897-912 (1981). https://doi.org/10.2514/3.57579

21. Gogulapati, A., Deshmukh, R., Crowell A. R. McNamara, J.J., Vyas, V., Wang, X.Q., Mignolet, M., Beberniss, T., Spottswood, S.M., Eason, T.G.: Response of a Panel to Shock Impingement: Modeling and Comparison with Experiments. In: 55th AIAA/ASME/ASCE/AHS/ASC Structures, Structural Dynamics, and Materials Conference, January. American Institute of Aeronautics and Astronautics (2014). https://doi.org/10.2514/6.2014-0148

22. Gogulapati, A., Deshmukh, R., McNamara, J.J., Vyas, V., Wang, X., Mignolet, M.P., Beberniss, T., Spottswood, S.M., Eason, T.G.: Response of a Panel to Shock Impingement: Modeling and Comparison with Experiments - Part 2. In: 56th AIAA/ASCE/AHS/ASC Structures, Structural Dynamics, and Materials Conference, January. American Institute of Aeronautics and Astronautics, Kissimmee, Florida (2015). https://doi.org/10.2514/6.2015-0685

23. Grilli, M., Chen, L.S., Hickel, S., Adams, N., Willems, S., Gülhan, A.: Experimental and numerical investigation on shockwave/turbulent boundary layer interaction. In: 42nd AIAA Fluid Dynamics Conference and Exhibit (2012)

24. Gülhan, A., Esser, B.: A Study on Heat Flux Measurements in High Enthalpy Flows. In: 35th AIAA Thermophysics Conference, Paper AIAA, June (2001). https://doi.org/10.2514/6.20013011

25. Gülhan, A., Esser, B.: Arc-Heated Facilities as a Tool to Study Aerothermodynamic Problems of Reentry Vehicles, Progress in Astronautics and Aeronautics, vol. 198, chap. 13, pp. 375-403. American Institute of Aeronautics and Astronautics, Reston (2002). https://doi.org/10.2514/5. 9781600866678.0375 .0403

26. Haidn, O.J., Adams, N.A., Sattelmayer, T., Stemmer, C., Radespiel, R., Schröder, W., Weigand, B.: Fundamental Technologies for the Development of Future Space Transportsystem Components under High Thermal and Mechanical Loads. In: 2018 Joint Propulsion Conference. 
American Institute of Aeronautics and Astronautics (2018). https://doi.org/10.2514/6.20184466

27. Haupt, M., Niesner, R., Esser, B., Gülhan, A.: Model Configuration for the Validation of Aerothermodynamic Thermal-Mechnical Fluid-Structure-Interactions. In: Proceedings of the ASME 2012 11th Biennial Conference On Engineering Systems Design And Analysis, ESDA2012/82908. Nantes, France (2012)

28. Hirschel, E.H., Weiland, C.: Selected Aerothermodynamic Design Problems of Hypersonic Flight Vehicles. Springer-Verlag, Berlin Heidelberg New York (2009)

29. Jenkins, J.M., Quinn, R.D.: A Historical Perspective of the YF-12A Thermal Loads and Structures Program. Tech. Rep. NASA Technical Memorandum 104317, NASA, Dryden Flight Research Center, Edwards, Ca (1996)

30. Kontinos, D.: Coupled Thermal Analysis Method with Application to Metallic Thermal Protection Panels. Journal of Thermophysics and Heat Transfer 11(2), 173-181 (1997). https:// doi.org/10.2514/2.6249

31. Koschel, W.: Flight 157 - Ariane 5 ECA: Report of the Inquiry Board. Tech. rep, European Space Agency (2003)

32. Kröplin, B.H., Kochendörfer, R., Reimer, T., Ullmann, T., Kornmann, R., Schäfer, R., Wallmersperger, T.: Basic Research and Technologies for Two-Stage-to-Orbit Vehicles: Final Report of the Collaborative Research Centres 253, 255 and 259, chap. Design and Evaluation of Fibre Ceramic Structures, pp. 549-580. Deutsche Forschungsgemeinschaft (2005)

33. Mack, A.: Analyse von heißen Hyperschallströmungen um Steuerklappen mit Fluid-StrukturInteraktion. Ph.D. thesis, DLR/Technische Universität Braunschweig (2005)

34. Mack, A., Schäfer, R.: Fluid Structure Interaction on a Generic Body-Flap Model in Hypersonic Flow. Journal of Spacecraft and Rockets 42(5), 769-779 (2005). https://doi.org/10.2514/1. 13001

35. Maestrello, L., Linden, T.L.J.: Measurements of the response of a panel excited by shock boundary-layer interaction. Journal of Sound and Vibration 16(3), 385-391 (1971). https:// doi.org/10.1016/0022-460X(71)90594-3

36. Martin, K., Daub, D., Esser, B., Gülhan, A., Reese, S.: Future Space-Transport-System Components under High Thermal and Mechanical Loads, chap. Numerical modelling of fluid-structure interaction for thermal buckling in hypersonic flow. Springer (2020)

37. Martin, K., Reese, S.: Thermo-Mechanically Coupled Fluid Structure Interaction for Thermal Buckling. In: VIII International Conference on Computational Methods for Coupled Problems in Science and Engineering (2019)

38. McNamara, J.J., Friedmann, P.P.: Aeroelastic and Aerothermoelastic Analysis in Hypersonic Flow: Past, Present, and Future. AIAA Journal 49(6), 1089-1122 (2011). https://doi.org/10. 2514/1.j050882

39. Mei, C., Abdel-Motagaly, K., Chen, R.: Review of Nonlinear Panel Flutter at Supersonic and Hypersonic Speeds. Applied Mechanics Reviews 52(10), 321-332 (1999). https://doi.org/10. $1115 / 1.3098919$

40. Miller, B., McNamara, J., Spottswood, S., Culler, A.: The impact of flow induced loads on snap-through behavior of acoustically excited, thermally buckled panels. Journal of Sound and Vibration 330(23), 5736-5752 (2011). https://doi.org/10.1016/j.jsv.2011.06.028

41. Nichols, J.: Final Report: Saturn V, S-IVB Panel Flutter Qualification Test. Tech. Rep. TN D-5439, NASA, George C. Marshall Space Flight Center, Marshall, Alabama (1969)

42. Niesner, R.: Gekoppelte Simulation thermisch-mechanischer Fluid-Struktur-Interaktionen für Hyperschall-Anwendungen. Ph.D. thesis, Technische Universität Braunschweig (2009)

43. Niezgodka, F.J.: Der Hyperschallwindkanal H2K des DLR in Köln-Porz (Stand 2000). DLR, Köln (2001)

44. Pasquariello, V., Hickel, S., Adams, N., Hammerl, G., Wall, W.A., Daub, D., Willems, S., Gülhan, A.: Coupled simulation of shock-wave/turbulent boundary-layer interaction over a flexible panel. In: 6th European Conference for Aerospace Sciences. EUCASS, Krakow (2015)

45. Pasquariello, V.: Analysis and Control of Shock-Wave/Turbulent Boundary-Layer Interactions on Rigid and Flexible Walls. Phd thesis, Technische Universität München, München (2018) 
46. Pasquariello, V., Hickel, S., Adams, N.A.: Unsteady effects of strong shock-wave/boundarylayer interaction at high Reynolds number. Journal of Fluid Mechanics 823, 617-657 (2017). https://doi.org/10.1017/jfm.2017.308

47. Pozefsky, P.: Identifying Sonic Fatigue Prone Structures on a Hypersonic Transatmospheric Vehicle (ATV). In: AIAA 12th Aeroacoustics Conference. AIAA, San Antonio, TX (1989)

48. Schäfer, R.: Thermisch-mechanisches Verhalten heißer Strukturen in der Wechselwirkung mit einem umströmenden Fluid. Ph.D. thesis, DLR/Universität Kassel (2005)

49. Shahriar, A., Shoele, K., Kumar, R.: Aero-thermo-elastic Simulation of Shock-Boundary Layer Interaction over a Compliant Surface. In: 2018 Fluid Dynamics Conference. American Institute of Aeronautics and Astronautics (2018). https://doi.org/10.2514/6.2018-3398

50. Spottswood, S.M., Beberniss, T.J., Eason, T.G.: Full-field, dynamic pressure and displacement measurements of a panel excited by shock boundary-layer interaction. 19th AIAA/CEAS Aeroacoustics Conference AIAA (2013). https://doi.org/10.2514/6.2013-2016

51. Spottswood, S.M., Eason, T.G., Beberniss, T.J.: Influence of shock-boundary layer interactions on the dynamic response of a flexible panel. Proceedings of the International Conference on Noise and Vibration Engineering ISMA 2012, 603-616 (2012)

52. Spottswood, S.M., Beberniss, T.J., Eason, T.G., Perez, R.A., Donbar, J.M., Ehrhardt, D.A., Riley, Z.B.: Exploring the response of a thin, flexible panel to shock-turbulent boundary-layer interactions. Journal of Sound and Vibration 443, 74-89 (2019). https://doi.org/10.1016/j.jsv. 2018.11.035

53. Thornton, E.A.: Thermal structures: Four decades of progress. Journal of Aircraft 29(3), 485498 (1992). https://doi.org/10.2514/3.46187

54. Thornton, E.A., Dechaumphai, P.: Coupled Flow, Thermal, and Structural Analysis of Aerodynamically Heated Panels. Journal of Aircraft 25(11), 1052-1059 (1988). https://doi.org/10. 2514/3.45702

55. Thornton, E.A., Oden, J.T., Tworzydlo, W.W., Youn, S.K.: Thermoviscoplastic Analysis of Hypersonic Structures Subjected to Severe Aerodynamic Heating. Journal of Aircraft 27(9), 826-835 (1990). https://doi.org/10.2514/3.45943

56. Visbal, M.: On the interaction of an oblique shock with a flexible panel. Journal of Fluids and Structures 30, 219-225 (2012). https://doi.org/10.1016/j.jfluidstructs.2012.02.002

57. Visbal, M.: Viscous and inviscid interactions of an oblique shock with a flexible panel. Journal of Fluids and Structures 48, 27-45 (2014). https://doi.org/10.1016/j.jfluidstructs.2014.02.003

58. Watts, J.D.: TM X-1669: Flight Experience with Shock Impingement and Interference Heating on the X-15-2 Research Airplane. Tech. rep, National Aeronautics and Space Administration (1968)

59. Willems, S., Gülhan, A., Esser, B.: Shock induced fluid structure interaction on a flexible wall in supersonic turbulent flow. In: Progress in Flight Physics - Volume 5, vol. 5, pp. 285-308 (2013). https://doi.org/10.1051/eucass/201305

60. Willems, S.: Strömungs-Struktur-Wechselwirkung in Überschallströmungen. Ph.D. thesis, DLR/RWTH Aachen University (2017). URL https://elib.dlr.de/116735/

61. Willems, S., Esser, B., Gülhan, A.: Experimental and numerical investigation on thermal fluidstructure interaction on ceramic plates in high enthalpy flow. CEAS Space Journal 7(4), 483497 (2015). https://doi.org/10.1007/s12567-015-0101-5 
Open Access This chapter is licensed under the terms of the Creative Commons Attribution 4.0 International License (http://creativecommons.org/licenses/by/4.0/), which permits use, sharing, adaptation, distribution and reproduction in any medium or format, as long as you give appropriate credit to the original author(s) and the source, provide a link to the Creative Commons license and indicate if changes were made.

The images or other third party material in this chapter are included in the chapter's Creative Commons license, unless indicated otherwise in a credit line to the material. If material is not included in the chapter's Creative Commons license and your intended use is not permitted by statutory regulation or exceeds the permitted use, you will need to obtain permission directly from the copyright holder. 